\title{
El desafío ético \\ del respeto a las muchas verdades. Universidad, ciencia y otros saberes
}

\author{
Francisca Márquez \\ Antropóloga, Departamento de Antropología, Universidad Alberto Hurtado, \\ Santiago, Chile. \\ Email: fmarquez@uahurtado.cl
}

\begin{abstract}
Resumen: La historia de las ciencias sociales en Latinoamérica indica que no habrá una virtuosa relación entre ciencia y sociedad en nuestro continente, si no se asume y revisa el complejo entramado de las estructuras sociales, de los poderes ysaberes que subyacen a nuestras culturas. Para articular el quehacer de los intelectuales e investigadores a las interrogantes de nuestras sociedades, el desafío es no sólo comprender los problemas que las estructuras sociales y campos de intereses no plantean, sino también, los saberes otros, con los que la ciencia debe aprender a dialogar.
\end{abstract}

Palabras clave: ética, ciencia, conocimiento, epistemología

\section{The ethical challengeof respectingthe many truths. University, science andother knowledges}

\begin{abstract}
Thehistory of social sciencesin Latin Americaindicatesthat there will not bea virtuous relationship betweens cience and society inour continent, if we do not assumeand review thecomplex web ofsocial structures, of power and of knowledgeunderlyingour cultures. To articulate the workof intellectualsand researchers on the questions ofour societies, the challenge is not only to underst and the problems that social structures and fieldsof interest do notpose, but alsothe knowledges others, with which science mustlearn to dialogue.
\end{abstract}

Keywords: ethics, science, knowledge, epistemology

\section{O desafio ético de respeitar as muitas verdades. Universidade, ciência e outros saberes}

Resumo: A história das ciências sociais na América Latina indica que não haverá uma relação virtuosa entre ciência e sociedade no nosso continente, se não é assumida e revisada a complexa teia de estruturas sociais, dos poderes e saberes que subjacem às nossas culturas. Para coordenar o trabalho de intelectuais e pesquisadores para as questões da nossa sociedade, o desafio não é somente entender os problemas que as estruturas sociais e campos de interesse não colocam. Mas também, ossaberesoutros, com os quais a ciência deve aprender a dialogar.

Palavras-chave: ética, ciência, conhecimento, epistemología. 
En América Latina,el pensamiento social se encuentra inmerso en las diversas formas de entender y construir el Estado, la Nación y la democracia. Históricamente el quehacer de las ciencias sociales se relaciona a la discusión de las pertenencias nacionales. Esa búsqueda conceptual hace parte de un campo intelectual atravesado por polémicas teóricas con implicancias prácticasy políticas. En la constitución de nuestros Estados nacionales estasconceptualizaciones a veces divergentes, estánpresente desde la ruptura colonial hasta hoy día. Los debates sobre la Nación, el Estado y sus condiciones de viabilidad no son, sin embargo, capítulos cerrados; ellos atraviesan hasta la actualidad la producción teórica y el quehacer de los intelectuales latinoamericanos.La producción científica brasileña, mexicana, peruana, ecuatoriana o colombiana son buenos ejemplos de esta relación crítica y aplicada de la disciplina de las ciencias sociales y humanas.

En el caso del desarrollo de las ciencias sociales en Chile, su aparición es tardía y en especial su participación en los debates latinoamericanos. Ello se explica en parte por la tendencia intelectual y política de observar y proponer la homogeneidad de la población chilena como una virtud de nuestra nación. Alejada de los críticos y complejos debates de países como México, Perú o Brasil, las ciencias sociales chilenas nacen a comienzos del siglo XX, con una fuerte improntaevolucionista, estableciéndose un cierto menosprecio acerca de las sociedades prehispánicas, lo indígena,lo mestizo, sus culturas y saberes. De allí el carácter conservador y folclorizantede los orígenes de las ciencias sociales en general en nuestro país. A pesar de los esfuerzos pioneros de algunos cientistas sociales, en especial antropólogos, por rescatar los fragmentos de las culturasy saberes originarios, no será sino hasta fines de los años cincuenta que se inicien los estudios sobre las culturas prehispánicas influenciados por ideas del indigenismo mexicanoquetardíamente llega a Chile.Será recién a mediados de la década de los sesenta que las ciencias socialeslograránabrirse anuevos campos y objetos de estudio. Si alguna ciencia social crítica se iniciaba en esas décadas, ello termina abruptamente en 1973 con el golpe militar. Ciertamente la dictadura no hizo más que profundizar la distancia entre el quehacer de las ciencias sociales en las universidades, los problemas nacionales y las culturas diversas que se encuban en nuestro país. Durante esos 17 años de dictadura, el pensamiento crítico no tuvo lugar al interior de las aulas universitarias. Hoy, a pesar de la proliferación de universidades, de cientistas sociales y de fondos para la investigación social, este debate está aún en construcción.

\section{II}

La historia de las ciencias sociales en Latinoamérica, nos indica que no podemos hablar de sus desafíos y compromisos, si no se asume el com- 
plejo entramado de las estructuras y de los poderes en los que se inserta. Para articular los saberes de los intelectuales al devenir de nuestras sociedades hay que saber con qué estructuras, campos de intereses sociales y culturas tendremos que vérnosla. Pero sobre todo, con que saberes otros, la ciencia deberá dialogar.

Hasta hoy díael resguardo institucional del saber legítimo se ejerce circunscribiendo sus objetos y métodos al orden de las disciplinas según especialización del conocimiento científico.Es esta compartimentación disciplinar la queda forma al diseño institucional de las universidadesy sus diseños curriculares e investigativos.Paradojalmente, las universidades, centros del pensamiento y el saber científico, parecieran haber quedado desfasadas y ajenas a las desarticulaciones y fragmentaciones del pensamiento moderno que rompe conla ilusión de totalidad y universalidad del conocimiento (Richards, 1995). Las universidades de hoypermanecen también ajenas a las evidencias socioculturales que indican que las fronteras del saber se extienden más allá de las aulas y esos saberes también exigen tener voz. Es el caso de los movimientos sociales indígenas en nuestros países, de los pescadores artesanales, los mineros, los movimientos estudiantiles, los movimientos de los indignados, los movimientos de vecinos que exigen resguardos medioambientales, de los vagabundos y andantes de nuestras ciudades, etc. En todos ellos, hay saberes otros, que exigen el derecho a un lugar en la construcción del conocimientoy en la toma de las decisiones.

Sin embargo, el mundo de las universidades pareciera resistirse a dichas evidencias, y aún ejerce su autoridad institucional marcando la distinción entre los saberes legítimos, autorizados, de los saberes ilegítimos. Durante los años de la dictadura chilena, esa división entre saberes autorizados y saberes prohibidos, fue radical. Mientras los primeros se recluyen en el marco de las especializaciones disciplinarias, los saberes otros transitan fuera de los muros universitarios anunciando el desconcierto y el desorden sobre los saberes científicos (Richards, 1995).

Sabemos quelas experiencias del conocimiento siempre implican el enfrentamiento entre saberes: Los saberesde las disciplinas, de los archivos, de la escritura científica- tradicionalmente encerrados en las bibliotecas y aulas universitarias - y los saberes que nacen de lasprácticas concretas, cotidianas, rituales, corporalizadas,que circulanmás allá o más acá de dichas aulas universitarias. ¿Pero qué podría enseñarnosla observación y escucha de estos saberes otros, de estas prácticas, oralidades,cotidianidades y actos corporalizados?¿Qué saberes podrían aportarnosestos saberes que no hayan sido reconocidos por los saberes anclados en textos y documentos científicamente legitimados?¿¿ué conocimientos y saberes se esconden en los bailes y rituales del pueblo mapuche que se despliegan al ritmo del kultrún; o de los cuerpos desnudos de Lemebel y Casas sobre la yegua blanca entrando a la Universidad de Chile; ode los cuerpos empolvados de las pobladorasde ANDHA - Chile que se zambullen desesperadas en los espejos de agua del Palacio de la Moneda y trepan por sus rejas exigiendo 
una vivienda digna; o en los cuerpos de los travestis luciendo su orgullo gay frente a la Moneda; o en los ovarios de cartón cubiertos de rosarios sobre el portal de la Catedral invocando el derecho al aborto?

La compleja relación entre archivos, escritura y oralidad, saberes prácticos, en contextos de dominación, represión y trauma en nuestro continente y país, vuelve estas preguntas de la mayor relevancia si queremos repensar la relación entre el saber académico y la sociedad. En todos estos gestos y gritosciertamentesubyacen saberes porque en ellas hay también memorias, tradiciones y reclamos. En cada baile y movimientos del cuerpo se establecen reivindicaciones de agencia cultural. Todos estamos en escena, todos los actores participamos en simultáneo y entrelazados en este drama aunque no se tenga la capacidad de la escritura y se haya perdido incluso la capacidad del habla.Porque en ellas, la “agencia cultural” no es individual, sino colectiva; colectivos son cada uno de los movimientos, de los ritmos, de las acciones de representación y de la transmisión de saberes. Es esta condición la que le otorga su impronta epistemológica y política aestas prácticas y saberes-hacer.

Si la escritura desplazó y deslegitimó otros sistemas epistémicos y mnemónicos, con lasprácticas corporalizadas y no verbales estos saberesrecuperan su sitial como formas válidas de conocimiento. Son saberes encarnados en prácticas y corporalizadas, que están y existen en tanto están ahí, en actos efímeros y no reproducibles, y por eso tan difícilmente reprimibles. Lo fascinante es que aun desplegándose en los espacios públicos, cada una de estos saberes, acciones y movimientos permiten una agenciay nos conducen hacia significados que para revelarse requieren de nuestra presencia. La acción y el conocimiento allí desplegado se vuelven colectivos porque son públicos y abiertos.Movimientos y saberes que no necesariamente gozan de fácil traductibilidad, por lo que pueden permanecer enigmáticos e indescifrables a la cultura del lenguaje del archivo, letrado y científico. Las implicancias políticas de estos gestos en tanto saberes corporalizados, vivos, inasiblesy heterotópicos, hablan de saberes otros que no se corresponden con el archivo letrado, un archivo que niega y prohíbe las voces subalternas (Taylor, 2015). Las prácticas del cuerpo vienen entonces a desordenar las categorías y el orden cientificista, a subvertirlo y romper los marcos sociales de la memoria y el conocimiento disciplinar.

Ciertamente los saberes corporalizados adquieren especial relevancia en aquellas sociedades fuertemente traumatizadas donde la palabra ha sido largamente censurada, y en las que el archivo, el decreto, el bando militar y dictatorial, se ha impuesto sobre los cuerpos, los idearios e identidades. Es en estas sociedades, censuradas en sus posibilidades expresivas, donde el cuerpo adquiere el valor de productor y transmisor de conocimiento, saberes, memorias e identidades. Pero también, de simple espejo de las tensiones y heridas no resueltas, no cicatrizadas. En estos términos, son saberes corporalizados que operan como actos vitales de transferencia, al transmitir lo no-decible, lo que no se puede expresar a viva voz, ya sea por la represión que circunda a estos cuerpos, o simplemente porque el 
trauma y el dolor, aun no abren la posibilidad de verbalizar ni escribir, lo que aun subyace como trauma profundo.

¿Cuál es el requisito para que este diálogo se construya? Ciertamente el primer paso es romper la violencia simbólica de la comunicación entre saberes que se ignoran.De lo que se trata, no es de simple interdisciplinariedad, sino de co-construir saberes, objetos, sujetos, situacionesy campos de realidad aún desconocidos por unos y otros.Pensar el modo en que el saber universitariopueda hoy conectarse con la sociedad, con la diversidad, pasa por la pregunta por atravesar los límites de su saber, multiplicando los vínculos con los saberes locales y en movimiento. La defensa de esta heterogeneidad de saberes oblicuos supone un nuevo modelo de conocimiento, capaz de interrogar sus propias convenciones discursivas y cientificistas. La experiencia y la práctica encarnada en los cuerpos y cotidianidades adquiere así valor como construcción epistemológica. De allí entonces la posibilidad de abrir espacios hacia formas de saberes situados, colectivosy descentrados. Para ello se requiere ciertamente revisar los protocolos del discurso naturalizado de la coherencia científica y positivista.

\section{III}

Históricamente, las ciencias sociales se han pensado en la definición de problemas aplicados a la resolución de preguntas que a la sociedad le preocupan. Es la diferencia entre una ciencia básica y una ciencia aplicada, siendo laprimera, la base de la construcción de saberes que luego tendrán su alcance aplicado.Pero una ciencia social comprometida, es algo que no ha estado presente de la misma manera y no goza de la misma legitimidad al interior de las aulas universitarias.Tradicionalmente ha existido colaboración entre las universidades y las comunidades, en la investigación base, en la ayuda en la formación de comunidades, en la búsqueda de recursos para la acción sociopolítica. La pregunta hoy sin embargo, es como avanzar hacia una universidad comprometida con los saberes otros, esos que por largo tiempo se encuban en las comunidades; como fortalecer esos lazos, ya no sólo unilateralmente, sino que esos lazossean de mutua reciprocidad en la perspectiva de una co-producción de conocimiento. Porque no toda la ciencia aplicada ha gozado del compromisocomo co-productoras de conocimiento, de ese diálogo en igualdad de condiciones.

Preguntarse por la relación entre la ciencia y su entorno es un tema complejopor varias razones. La primera es que la pregunta por el saber y por la axiología de la ciencia, nace justamente cuando la ciencia observa las consecuencias (a veces nefastas) de su producción de conocimiento.La cuestión ética y de cuestionamiento a sus propios saberes, adquiere toda su fuerza cuando los estragos sobre las comunidades estudiadas comienzan a observarse. La segunda complejidad de esta pregunta, reside en el hecho que nos obliga a releer y revisar el quehacer científico en su totalidad y no solo en sus resultados.Es decir, el cuestionamiento y la respuesta a los 
problemas generados por la investigación científica, necesita incorporar el análisis del proceso investigativo completo. Y es aquí, justamente, donde los supuestos de objetividad de la ciencia tienden a estrellarse con la evidencia de que los criterios del saber, como asimismo los criterios éticos pueden ser muy distintos según los contextos desde donde se levanten. La diversidad de contextos de producción de saberes nos deja en evidencia también, que el ethos del científico social siempre tendrá que vérselas con otros ethos y otras éticas. Una axiología de la ciencia social, por esencia deberá saber dialogar con esas otras axiologías de saberes y haceres. En este sentido, más que verdades, del quehacer científico y en especial de las ciencias sociales, se demandan perspectivas para comprender las formas en que hemos estructurado nuestros conocimientosy como ellos alteran nuestra convivencia (Hirsch, 2004; Roig, 2007). Plantear la responsabilidad de la ciencia es hacerse cargo de ese desafío ético del respeto a las muchas verdades. La verdad o las verdades son patrimonio de todos los seres humanos; compatibilizar el rigor científico con la transparencia y la responsabilidad ética con dichas verdades esun desafío. Para las ciencias sociales en su conjunto, esto es especialmente relevante por cuanto su objeto de estudio son justamente las sociedades y el método obliga a desarrollar relaciones próximas con personas.La discusión ética parte de la premisa que la generación y uso apropiado del conocimiento de y desde las comunidades posee como fin el resguardo y respeto de las culturas. Pero también se reconoce que la generación del conocimiento social es un proceso que se vale de perspectivas diferentes y en constante cambio. Son estas premisas que, por razones morales y prácticas, hacen relevante que la generación y utilización de este conocimiento deba ser obtenido atendiendo consideraciones éticas (AAA, 1998: 3, 4).

Ciertamente, este desafío ético del respeto a los otros saberes, exige adherir a un lenguaje común, transparente en el sinceramiento de los propios intereses y búsquedas. Pero por sobre todo, exige que el cientista social sea capaz de "objetivar su participación” o presencia en el lugar(Bourdieu, 2003: 43). Sincerarlas propias interrogantes al interior de la comunidad estudiada, es la principal exigencia para una investigación social éticamente responsable. Construir los límites de la relación es un trabajo de todos, pero crear las condiciones para que ello sea factible, es responsabilidad del cientista social.

De allí entonces la importancia de la pregunta por la objetivación de esa participación en el lugar. Es Bourdieu, sociólogo, quien instala la duda con respecto a la ilusión de la empatía con el nativo y sus culturas, como garantía de comprensión y respeto de esa otredad (Bourdieu y Waquant, 1992; Bourdieu, 1999; Bourdieu, 2003). Para las ciencias sociales el problema es especialmente complejo, en un mundo letrado, el quiebre de la autoridad intelectual dice relación con el cuestionamiento a la superioridad del científico en la interpretación y comprensión de la realidad social. Ciertamente, ni la experiencia ni la actividad interpretativa del científico pueden considerarse inocentes. La investigación social más que la interpretación de "otra" realidad, es siempre una negociación constructiva que involucra 
a dos y más sujetos. No hay significado discursivo sin interlocución y contexto (Bourdieu, 1999).

Hoy parece indispensable insistir en la necesidad de explicitar las intenciones y los procedimientos que se ponen en práctica en las investigaciones sociales. En términos de Bourdieu, de explicitar y objetivar la propia participación en la investigación y en la comunidad involucrada. Sea cual sea el objetivo de la investigación,siempre conllevan una relación social que genera efectos sobre los resultados obtenidos.Para Bourdieu, sólo la reflexividad, que es sinónimo de método -pero una reflexividad refleja, fundada sobre un oficio -permite percibir y controlar sobre la marcha en la realización de la investigación los efectos del contexto y de la interacción.El sueño positivista de una perfecta inocencia epistemológica, nos advierte Bourdieu, enmascara el hecho de que la diferencia no es entre la ciencia que efectúa una construcción y la que no lo hace, sino entre la que lo hace sin saberlo y la que sabiéndolo, se esfuerza por conocer y dominar lo más completamente posible sus actos y los efectos que estos producen. La objetivación es una exigencia ética del investigador y ella supone, en estos términos, analizar las condiciones sociales de posibilidad de tal experiencia de investigación. En estos términos, construir una ética de las ciencias sociales exige partir de la base de una ontología que se niega a separar y a oponer objeto y sujeto.

Si en su etapa fundante, a las ciencias sociales no le cabía duda que era el científico, a menudo mandatado porintereses colonialistas, quien definía esa verdad y esa autoridad; hoy dicha "autoridad científica" no se sostiene ni legítima en términos epistémicos y axiológicos si no se amarra a una verdad compartida, polifónica y enraizada en un perspectivismo. En este aspecto, los resultados de la investigación y el conocimiento científico pertenecen a todos, por ende los cientistas sociales son responsables pública y políticamente del conocimiento generado.

¿Cómo describir y respetar éticamente las diferencias y las formas culturales que compiten para ser representadas en este tiempo y espacio que es la cultura nacional? El desafío de una representación éticamente responsable es el retrato comprensivo de estos encuentros locales y globales con todo lo que ellos poseen de saberes, deliberación, dominación y resistencia, oralidad y experiencia. Una mirada multisituada de los desplazamientos tanto en los lugares de exclusión como de dominación.

El problema no está ciertamente en las voluntades de cada individuo, el problema está en las violencias estructurales, simbólicas y normalizadoras de nuestras sociedades desiguales. Cuando esta trialéctica confluye en una misma biografía, a pesar de los esfuerzos de cada individuo por sobreponerse a sus propias circunstancias, la lucha parece perdida. De allí el deber de toda ciencia de contribuir a generar estas bases mínimas del respeto, a través de"la superación de la mirada miserabilista y el cruce de miradas, hasta que las evidencias de las condicionantes estructurales salten a la vista” (Bourdieu, 1995).Lo cierto es que las capacidades de autode- 
terminación están desigualmente distribuidas en el tejido social y sean cuales sean los recursos y capitales, su disponibilidad, acceso, adquisición y uso, exceden siempre nuestras voluntades individuales. La trampa del neoliberalismo es hacernos pensar que "cualquier persona inteligente puede pasar de los harapos a la abundancia si trabaja con tesón” (Bourgois, 2014).

En síntesis, el desafío del cientista social, a través del ejercicio reflexivo y polifónico, continúa siendo elcontribuir a develar las estructuras profundas de este mundo social, así como los mecanismos que tienden a asegurar,a menudo de manera violenta, su reproducción o transformación. Sólo así, las ciencias sociales aportarán el reconocimiento del derecho de hombres y mujeres al ejercicio de la soberanía sobre sus vidas, sobre sus culturas y sobre sus saberes. Dejar lugar a la construcción de contra narrativas de la Nación, que evocan y borran sus fronteras totalizantes y homogeneizantes, puede ser un camino fructífero. Ejercicio que impedirá o al menos dificultará que nuestrosEstado Nación se cubran de identidades esencialistas y un discurso homogéneo y positivista del progreso. 


\section{Bibliografía}

AAA (1998), Código De Ética de La Asociación Antropológica Americana. Aprobado en junio 1998. Traducción de Debbie Guerra y Juan Carlos Skewes, Valdivia, 1 de marzo 2003.

Bourdieu, Pierre (2003), “L'objectivationparticipante”, en: Actes de la recherche en sciences sociales, $\mathrm{N}^{\circ} 150$, pp. 43-58, Paris.

Bourdieu, Pierre y Waquant, L. (1992), Résponses. Seuil, París.

Bourdieu, Pierre (1999), La miseria del mundo, Fondo de Cultura Económica, Buenos Aires.

Ídem (1995), "Crisis de los saberes y espacio universitario en el debate contemporáneo”, en: Arcis, La invención y la herencia, Ed.Lom,Santiago.

Bourgois, Philippe (2014), En busca de respeto. Vendiendo crack en Harlem. Siglo XXI, Buenos Aires, Argentina.

Hirsch, Ana (2004), “Ética de la ciencia y de la investigación científica”, en Ethos Educativo 30, México, mayo-agosto, pp.113-140.

Krotz, Esteban (2007),“Las Antropologías latinoamericanas como segundas: situaciones y retos”, en Fernando García (ed.), II Congreso Ecuatoriano de Antropología y Arqueología. Balance de la última década: Aportes, Retos y nuevos temas. Vol. I, pp. 41-59. Abya-Yala, Quito.

Márquez, Francisca (2013), "De los invisibles y el derecho al anonimato. Apuntes para una ética en la investigación social”, en: CONICYT, Protección de las personas en la investigación científica, Taller de Bioética organizado por Comité Asesor de Bioética Fondecyt de CONICYT Santiago, pp.89 -94.

Richard, Nelly (1995), La invención y la herencia, U.Arcis, Ed. Lom, Santiago.

Roig, Arturo (2007), Ética del poder y moralidad de la protesta: La moral latinoamericana de la emergencia, http://ensayistas.org/filosofos/argentina/roig/etica/etica10.html (24.01.2015)

Taylor, Diana (2015), El archivo y el repertorio. La memoria cultural performática en las Américas. Ed. Universidad Alberto Hurtado: Colección Antropología, Santiago. 